\title{
Abnormal Sodium Transport in Synaptosomes from Brain of Uremic Rats
}

Cosmo L. Fraser, Philip Sarnacki, and Allen I. Arieff

Division of Nephrology, Department of Medicine, Veterans Administration Medical Center, and

University of California at San Francisco, California 94121

\begin{abstract}
The causes of central nervous system (CNS) dysfunction in uremia are not well known and are not completely reversed by dialysis. This problem was investigated in synaptosomes, which are membrane vesicles from synaptic junctions in the brain. We measured $\mathrm{Na}$ uptake under conditions of control, veratridine stimulation, and tetrodotoxin inhibition, in synaptosomes from normal and acutely uremic (blood urea nitrogen, $250 \mathrm{mg} / \mathrm{dl}$ ) rats. In the control state, maximal $\mathrm{Na}$ uptake was $2.2 \pm 0.2$ and $1.9 \pm 0.3 \mathrm{nmol} / \mathrm{mg}$ of protein in normal and uremic synaptosomes, respectively. With veratridine stimulation, $\mathrm{Na}$ uptake was increased by 1.9 and $3.6 \mathrm{nmol} / \mathrm{mg}$ of protein in normal vs. uremic rats $(P<0.001)$. The increased veratridine-stimulated $\mathrm{Na}$ uptake observed in uremia could be due either to increased membrane permeability to $\mathrm{Na}$ or decrease in the $\mathrm{Na}-\mathrm{K}$ ATPase pump activity. To investigate this, we studied the Na-K ATPase pump function by evaluating uptake of $K$ (using rubidium as a tracer), uptake of $\mathrm{Na}$ during ATP stimulation, and inhibition of $\mathrm{Rb}$ and $\mathrm{Na}$ uptake by ouabain. In uremic rats both $\mathbf{R b}$ uptake and ATP-stimulated Na uptake were significantly less than in normals $(P<0.005)$. This suggests a defect in the Na-K ATPase pump. Membrane permeability for $\mathrm{Na}$ was then evaluated both by measuring initial $\mathrm{Na}$ uptake, and with addition of valinomycin. No change in $\mathrm{Na}$ uptake pattern was observed with valinomycin, and initial $\mathrm{Na}$ uptake was not significantly different in normal versus uremic synaptosomes. These data show that $(a)$ in uremic rats veratridine-stimulated $\mathrm{Na}$ accumulation is significantly greater than normal; (b) the increased $\mathrm{Na}$ accumulation observed in uremia appears to be due to alterations in Na-K ATPase pump activity; and (c) the altered $\mathrm{Na}$ accumulation observed is probably not due to a uremic environment, but may be secondary to a physiologic alteration in synaptosomal function due to the uremic state. These abnormalities may affect neurotransmission and may be associated with the CNS alterations observed in uremia.
\end{abstract}

\section{Introduction}

Central nervous system dysfunction is a major complication of the uremic state. The clinical manifestations have been well described in several review articles (1). The biochemical basis for central nervous system dysfunction of uremia is not well

This study was presented in part at the annual meeting of the American Society for Clinical Investigation, Washington, DC, May 1984

Dr. Cosmo L. Fraser was a Research Fellow of the National Kidney Foundation and is presently an Associate Investigator of the Veterans Administration.

Address correspondence to Dr. Fraser, Veterans Administration Medical Center (111J), 4150 Clement St., San Francisco, CA 94121.

Received for publication 21 March 1984 and in revised form 1 February 1985

The Journal of Clinical Investigation, Inc.

Volume 75, June 1985, 2014-2023 understood and is only partially corrected by dialytic therapy. Studies of the central nervous system in humans with renal failure and in animal models of renal failure have revealed no consistent pathologic changes (2). Biochemical studies in the brain of animal models with renal failure have also been generally unrevealing. The brain content of several ions $(\mathrm{Na}$, $\mathrm{K}, \mathrm{Mg}, \mathrm{Cl}$, bicarbonate) and water are not abnormal $(2,3)$, and brain intracellular $\mathrm{pH}\left(\mathrm{pH}_{\mathrm{i}}\right)$ is also normal (3). Brain content of high-energy phosphate compounds (ATP, phosphocreatine) is normal, although their turnover rate appears to be decreased (4). There may be altered permeability of the uremic brain to certain molecules, such as sodium, potassium, and inulin (5).

Among the few positive findings in uremic brain is an increased brain content of calcium, which appears to be parathyroid hormone (PTH) ${ }^{1}$ dependent (6). There are also associated abnormalities of the electroencephalogram, which are PTH dependent $(7,8)$. In addition, increased levels of aluminum in the brain may be related to some forms of uremic encephalopathy (9). However, removal of certain potential "uremic neurotoxins," such as aluminum or PTH, does not reverse uremic encephalopathy, although parathyroidectomy in uremic subjects does result in improvement both in physiologic testing and the electroencephalogram (10). Thus, other biochemical alterations are most likely present. Elucidation of these abnormalities would be difficult in in vivo whole animal models.

In using in vitro systems, other investigators have found abnormalities in both enzyme activity and certain transport phenomena. In erythrocytes from uremic subjects, both Welt and associates $(11,12)$ and Woods and co-workers (13) have shown abnormalities of sodium transport. In extracts from uremic rat brain, the Na-K ATPase enzyme activity has been reported to be normal to low $(14,15)$.

There are subcellular systems available for studies of brain metabolism. One such system is the synaptosome. When brain tissue is homogenized in isoosmotic solution, the bulblike presynaptic nerve endings are sheared off and resealed to form intact vesicles. These vesicles are called synaptosomes, and they function morphologically and biochemically as intact nerve endings do (16). Similarly to nerve terminals, the synaptosomes contain synaptic vesicles, mitochondria, and cytoplasmic volume $(17,18)$ and are metabolically active. The synaptosome can be studied as an intact system or be lysed into its constituents and ghost synaptic plasma membrane (19). Synaptosomes have been used for the investigation of synthesis, storage, and release of neurotransmitter substances; ion transport and the effect of various drugs and toxins on numerous metabolic processes have also been studied (20-24). Because of the unique properties of synaptosomes, they ap-

1. Abbreviations used in this paper: LDH, lactate dehydrogenase; MOPS, 3-( $N$-morpholino)propane sulfonic acid; PTH, parathyroid hormone. 
peared to be an appropriate model to investigate the effects of uremia on the central nervous system.

\section{Methods}

General. Experiments were performed on 200-g male Sprague-Dawley rats and were carried out in paired groups of normal and uremic rats. The rats were made acutely uremic (blood urea nitrogen, $250 \mathrm{mg} / \mathrm{dl}$ ) by performing bilateral ureteral ligation under general anesthesia (ketamine, $150 \mathrm{mg} / \mathrm{kg}$ of body wt) administered intramuscularly. They were then placed in cages and fed regular rat laboratory diet and had free access to water along with the control groups. At $45 \mathrm{~h}$, the rats were killed by decapitation and their forebrains were removed and immediately placed in $10 \mathrm{ml}$ of ice-cold isolation medium $(320 \mathrm{mM}$ sucrose, $0.2 \mathrm{mM} \mathrm{K-EDTA,} 5 \mathrm{mM}$ Tris- $\mathrm{HCl}, \mathrm{pH} 7.4)$ at $0-4^{\circ} \mathrm{C}$. The normal and uremic brains were processed simultaneously, but kept separately in distinctly marked containers. For each experiment, four rat brains were pooled for isolation of synaptosomes. All further experiments were carried out at $0-4^{\circ} \mathrm{C}$.

Isolation of synaptosomes. Synaptosomes were prepared by modification of the method of Gray and Whittaker (25). The brains were chopped finely with scissors and rinsed three times with $5-10 \mathrm{ml}$ of isolation media to remove any blood. The extract was then brought up to a volume of $15 \mathrm{ml}$ with isolation media and poured into a glass Dounce homogenizer (clearance $1 \mathrm{~mm}$ ) and homogenized with 15 evenly pressured up and down strokes, pausing for $10 \mathrm{~s}$ after every three strokes to prevent the generation of heat by friction. The suspension was then brought up to $30 \mathrm{ml}$ with isolation media, divided equally into two glass centrifuge tubes, and spun at $1,300 \mathrm{~g}$ for $3 \mathrm{~min}$ with a centrifuge (model J21B; Beckman Instruments, Inc., Fullerton, CA). The supernatant $S_{1}$ was poured off and saved, while the pellet $P_{1}$ was resuspended in $15 \mathrm{ml}$ of isolation media by homogenization. The suspension was again centrifuged at $1,300 \mathrm{~g}$ for $3 \mathrm{~min}$, and both supernatants $S_{1}$ and $S_{2}$ were combined. The combination was centrifuged at $1,300 \mathrm{~g}$ for $3 \mathrm{~min}$, the pellet $P_{3}$ was discarded, and the supernatant $S_{3}$ was spun at $18,000 \mathrm{~g}$ for $10 \mathrm{~min}$ to obtain the crude synaptosomalmitochondrial pellet. The pellet was resuspended in $15 \mathrm{ml}$ of isolation media by homogenization with three strokes. Aliquots of $7.5 \mathrm{ml}$ were then layered upon a discontinuous Ficoll gradient consisting of $13 \mathrm{ml}$ of $11 \%$ Ficoll at the bottom of the centrifuge tube, upon which was layered $13 \mathrm{ml}$ of $7.5 \%$ Ficoll. Ficoll was dialyzed for $5 \mathrm{~h}$ before use. The gradient was then ultracentrifuged at $100,000 \mathrm{~g}$ for $70 \mathrm{~min}$ with an ultracentrifuge (model L5-50, SW28 rotor, Beckman Instruments, Inc.). On completion of the spin, the purified synaptosomes were located at the interface between the 11 and $7.5 \%$ Ficoll layers. The brown mitochondrial pellet was adherent to the bottom of the centrifuge tube, and a small band of myelin layer was found at the interface of the isolation media and $7.5 \%$ Ficoll layer. The synaptosomes were removed by suction with a plastic disposable pipette and the pellet was brought up to $20 \mathrm{ml}$ with ice-cold isolation media. It was then spun at $17,000 \mathrm{~g}$ for $10 \mathrm{~min}$ and the pellet was brought up to $15 \mathrm{ml}$ with isolation media. The suspension was divided into $0.5-\mathrm{ml}$ aliquots and stored at $-80^{\circ} \mathrm{C}$. The frozen synaptosomes were then able to be used for transport studies for periods of many months thereafter.

Protein determination. Protein concentration was determined as described by Lowry et al. (26). The extraction method yielded about $100 \mathrm{mg}$ of synaptosomal protein per $4 \mathrm{~g}$ of rat brain cortex. For calculation of the results, protein concentration was measured from the final synaptosomal suspension used for transport studies.

Total internal synaptosomal volume. This was determined by the method described by Padan and associates (27). [methoxy- ${ }^{14} \mathrm{C}$ ] Inulin was used to measure the external space and tritiated $\mathrm{H}_{2} \mathrm{O}$ was used to determine the total pellet water. Internal synaptosomal volumes during experimental condition were also assessed by using $\left[{ }^{3} \mathrm{H}\right]$ mannitol which was used as a marker for intracellular water (28). The synaptosomes were allowed to incubate in $\left[{ }^{3} \mathrm{H}\right]$ mannitol for $20 \mathrm{~min}$ before the initiation of uptake. The amount of ${ }^{3} \mathrm{H}$ taken up by the synaptosomes was measured simultaneously with ${ }^{22} \mathrm{Na}$ or ${ }^{86} \mathrm{Rb}$ at the end of the experiments.

ATP assay. Native intravesicular ATP was measured in the following manner. A $20-\mathrm{mg}$ aliquot of synaptosomal protein was thawed rapidly at room temperature. It was then suspended in $5 \mathrm{ml}$ of preequilibrium media consisting of $150 \mathrm{mM} \mathrm{KCl}, 1 \mathrm{mM} \mathrm{MgCl}$, and $5 \mathrm{mM} \mathrm{3-}(N-$ morpholino)propane sulfonic acid (MOPS)- $\mathrm{KOH}$ at $37^{\circ} \mathrm{C}, \mathrm{pH} 7.4$, and incubated for $10 \mathrm{~min}$. The suspension was spun at $10,000 \mathrm{~g}$ for $10 \mathrm{~min}$, and the pellet was resuspended to $10 \mathrm{mg} / \mathrm{ml}$ in the same media and incubated for $5 \mathrm{~min}$ at $25^{\circ} \mathrm{C}$. The incubation was terminated by adding perchloric acid to a $4 \%$ final concentration. After centrifuging at $10,000 \mathrm{~g}$ for $10 \mathrm{~min}$ the supernatant was removed and neutralized with $4 \mathrm{~N} \mathrm{KOH}, 0.8 \mathrm{~N} \mathrm{KCl}$, and $0.8 \mathrm{~N}$ imidazole, $\mathrm{pH} 7.5$. ATP was then analyzed by modification of the method described by Lowry and Passonneau (29).

Sodium uptake assay. For sodium influx studies $0.5-\mathrm{ml}$ aliquots of synaptosomal protein containing $\sim 8.0 \mathrm{mg} / \mathrm{ml}$ of protein was thawed at room temperature and allowed to incubate in $2.0 \mathrm{ml}$ of preequilibrium media (150 mM KCl, $1 \mathrm{mM} \mathrm{MgCl} 2,5 \mathrm{mM}$ MOPS-KOH, pH 7.4) for $10 \mathrm{~min}$ at $37^{\circ} \mathrm{C}$ in a manner similar to that of Gill (24). In some studies choline chloride was substituted for potassium chloride. The suspension was then centrifuged at $20,000 \mathrm{~g}$ for $5 \mathrm{~min}$, and the pellet was resuspended in $400 \mu \mathrm{l}$ of the same preequilibrium media and stored at $0-4^{\circ} \mathrm{C}$ until the transport studies were begun. Sodium uptake was started by adding $80 \mu \mathrm{l}$ of synaptosomal vesicles $(\sim 800 \mu \mathrm{g}$ of protein) to $1.52 \mathrm{ml}$ of external media, which then constituted the reaction media. The external media contained $140 \mathrm{mM}$ choline chloride, $5 \mathrm{mM} \mathrm{MgCl}, 0.2 \mathrm{mM}$ EGTA, $5 \mathrm{mM}$ MOPS-Tris, $\mathrm{pH} 7.4$, $1 \mathrm{mM} \mathrm{NaCl}, 5.2 \mu \mathrm{Ci}^{22} \mathrm{Na} \sim 16 \times 10^{6} \mathrm{cpm}$ at $25^{\circ} \mathrm{C}$. Depending on experimental protocol, the appropriate additions of inhibitors and stimulators of sodium uptake (ouabain, veratrine $\mathrm{HCl}$, tetrodotoxin, and valinomycin) were added to the external media. Veratrine is a mixture of four alkaloids, $25 \%$ of which is taken to be veratridine (23). After the desired periods of incubation the uptake was terminated by adding $100 \mu \mathrm{l}$ of the reaction media to $2 \mathrm{ml}$ of ice-cold $150 \mathrm{mM}$ choline chloride (stop solution). Each time point was done in triplicate. The mixture was immediately vacuum filtered through $0.45-\mu \mathrm{m}$ pore size cellulose-acetate membrane and washed twice with $2 \mathrm{ml}$ ice-cold stop solution. The filters were then dissolved in phase-combining system II scintillant and counted by a counter (model 2409; Packard Instrument Co., Inc., Downers Grove, IL). The zero time points were obtained by first adding $95 \mu \mathrm{l}$ of external medium to $2 \mathrm{ml}$ of the stop solution and then adding $5 \mu \mathrm{l}$ of synaptic vesicles ( $\sim 50 \mu \mathrm{g}$ of protein) to this mixture after the uptake was stopped. The mixture was filtered as above. Nonspecific binding to the filters was $\sim 0.01 \%$ of the total count and nonspecific binding to the protein was $\sim 0.03 \%$ of total.

Potassium uptake assay. In this experiment the vesicles were loaded with sodium by incubation for $10 \mathrm{~min}$ at $37^{\circ} \mathrm{C}$ in four times its volume of preequilibration media $(150 \mathrm{mM} \mathrm{NaCl}, 1 \mathrm{mM} \mathrm{MgCl}, 5$ $\mathrm{mM}$ MOPS-Tris, $\mathrm{pH}$ 7.4). It was then centrifuged at $20,000 \mathrm{~g}$ for 5 min, and the pellet was brought up in $400 \mu l$ of preequilibrium media and placed on ice. Uptake was started by addition of $5 \mu \mathrm{l}$ of synaptosomal suspension ( $\sim 50 \mu \mathrm{g}$ of protein) to $95 \mu \mathrm{l}$ of external media (140 mM choline chloride, $5 \mathrm{mM} \mathrm{MgCl}_{2}, 0.2 \mathrm{mM}$ EGTA, 1 $\mathrm{mM} \mathrm{KCl}, 5 \mathrm{mM}$ MOPS-KOH, pH 7.4, 0.5 $\mu \mathrm{Ci}^{86} \mathrm{Rb} 70,000 \mathrm{cpm}$ ) at $25^{\circ} \mathrm{C}$. The uptake was terminated at the prescribed time of incubation by immediately adding $100 \mu \mathrm{l}$ of the reaction mixture to $2 \mathrm{ml}$ of icecold stop solution. The mixture was then filtered through a $0.45-\mu \mathrm{m}$ pore size cellulose acetate membrane. The filters were washed twice with $2 \mathrm{ml}$ of cold stop solution (150 mM choline chloride) and dissolved in phase combining system II scintillation fluid before counting by a Packard counter (model 2409). The potassium uptake was then calculated on a one-to-one relationship with the rubidium uptake $(30,31)$.

ATP-stimulated Na uptake. The ATP-stimulated sodium uptake was commenced by preloading the synaptosomes with a $150 \mathrm{mM} \mathrm{KCl}$ preequilibration media as previously described. $5 \mu \mathrm{l}(\sim 50 \mu \mathrm{g}$ of protein) was then added to $95 \mu \mathrm{l}$ of external media consisting of 140 
$\mathrm{mM}$ choline chloride, $5 \mathrm{mM} \mathrm{MgCl}, 0.2 \mathrm{mM}$ EGTA, $5 \mathrm{mM}$ MOPSTris, $\mathrm{pH} 7.4,2.5 \mathrm{mM}$ Tris-ATP, $1 \mathrm{mM} \mathrm{NaCl}$, and $0.6 \mu \mathrm{Ci}^{22} \mathrm{Na}$ and allowed to incubate at $25^{\circ} \mathrm{C}$. The sodium uptake was terminated at the appropriate time of incubation by diluting the reaction mixture with the stop solution, and counting as discussed.

Valinomycin experiments. Aliquots of $4 \mathrm{mg}$ of synaptosomes were loaded in a solution containing $150 \mathrm{mM} \mathrm{KCl}, 1 \mathrm{mM} \mathrm{MgCl}_{2}, 5 \mathrm{mM}$ MOPS-KOH at $\mathrm{pH} 7.4$, for $10 \mathrm{~min}$ at $37^{\circ} \mathrm{C}$. It was then centrifuged at $20,000 \mathrm{~g}$ for $5 \mathrm{~min}$ and brought up in $400 \mu \mathrm{l}$ of the same media and stored on ice at $0-4^{\circ} \mathrm{C}$. Uptake was initiated by adding $5 \mu \mathrm{l}$ of synaptosomal fraction ( $\sim 50 \mu \mathrm{g}$ of protein) to $95 \mu \mathrm{l}$ of an external media containing $140 \mathrm{mM}$ choline chloride, $5 \mathrm{mM}$ MOPS-Tris, 0.2 mM EGTA, $5 \mathrm{mM} \mathrm{MgCl} 2,25 \mu \mathrm{M}$ valinomycin, $1 \mathrm{mM} \mathrm{NaCl}, 0.6 \mu \mathrm{Ci}$ ${ }^{22} \mathrm{Na}$. The reaction was terminated as discussed earlier.

Oxygen consumption study. Respiration of the synaptosomes was measured by a Clark-type oxygen electrode at $25^{\circ} \mathrm{C}$ in a manner similar to Booth and Clark (16). The incubation media contained 3.0 $\mathrm{ml}$ of $100 \mathrm{mM} \mathrm{NaCl}, 75 \mathrm{mM}$ mannitol, $25 \mathrm{mM}$ sucrose, $10 \mathrm{mM}$ phosphate-Tris, $10 \mathrm{mM}$ Tris-HCl, pH 7.4, $0.05 \mathrm{mM}$ K-EDTA. To this was added $10 \mu \mathrm{l}$ of synaptosomal protein together with $10 \mu \mathrm{l}$ of 10 $\mathrm{mM}$ glucose as substrate. Oxygen consumption was then calculated on the basis of temperature and protein concentration.

Enzyme assays. Contamination studies were performed at $25^{\circ} \mathrm{C}$ and at a wavelength of $550 \mathrm{~nm}$ using a recording spectrophotometer (model 240; Gilford Instrument Laboratories, Inc., Oberlin, $\mathrm{OH}$ ). Rotenone-insensitive NADH and NADPH cytochrome $c$ reductase assays were measured by modification of the method described by Duncan and Mackler (32). The reaction mixture consisted of $3 \mathrm{ml}$ of $0.3 \mathrm{mM} \mathrm{KCN}, 0.10 \mathrm{mM}$ NAD(P)H, $0.1 \mathrm{mM}$ cytochrome $c, 1.5 \mathrm{mM}$ rotenone, $50 \mathrm{mM} \mathrm{K}_{2} \mathrm{HPO}_{4}$ buffer, $\mathrm{pH} 7.4$, to which $10 \mu$ l of synaptosomal protein was added. The extinction coefficient of cytochrome was taken to be 21.1 (33).

Lactate dehydrogenase (LDH) activity was measured by following NADH oxidation at a wavelength of $340 \mathrm{~nm}$ in a medium containing $40 \mathrm{mM}$ potassium phosphate buffer, $\mathrm{pH} 7.4,1 \mathrm{mM}$ pyruvate, $0.2 \mathrm{mM}$ $\mathrm{NADH} \pm 0.5 \%$ Triton X-100 (34). The extinction coefficient of NADH was taken to be $6.22(35)$. The assay was carried out at $25^{\circ} \mathrm{C}$.

Materials. The chemicals used in these experiments were obtained from the following sources. ${ }^{22} \mathrm{NaCl},{ }^{86} \mathrm{RbCl},{ }^{3} \mathrm{H}_{2} \mathrm{O}$, [methoxy ${ }^{14} \mathrm{C}$ ]inulin, and $\left[{ }^{3} \mathrm{H}\right]$ mannitol were obtained from New England Nuclear (Boston, MA). Veratrine- $\mathrm{HCl}$ ( $25 \%$ of which is veratridine), tetrodotoxin, TrisATP, valinomycin, Ficoll, ouabain octahydrate, rotenone, EGTA, and EDTA were obtained from Sigma Chemical Co. (St. Louis, MO). Cellulose acetate filters, type SM 111-P12, were obtained from Sartorius Filters (Hayward, CA). Sprague-Dawley rats were obtained from Bainton-Kingman (Fremont, CA). All other chemicals were of reagent grade and were obtained from Sigma Chemical Co.

\section{Results}

Enzyme and contamination studies. The results of the degree of contamination of the synaptosomal fraction by free mito- chondria and endoplasmic reticulum are shown in Table I. In this experiment the activity of the rotenone-insensitive NADH and NADPH cytochrome $c$ reductase is used as marker. The NADH-cytochrome $c$ reductase is a marker for both the outer mitochondrial membrane and the endoplasmic reticulum (36, 37 ), whereas the NADPH-cytochrome $c$ reductase is specific only to the endoplasmic reticulum (36). Therefore the difference between the two enzyme markers and the calculated value of $42.0 \mathrm{~nm} / \mathrm{mg}$ protein of NADH for pure mitochondria allows us to calculate the degree of contamination with free mitochondria. From this calculation there are $\sim 6.4$ and $5.7 \%$ contamination of the normal and uremic synaptosomes, respectively. These values are consistent with those published by other investigators (16).

The integrity of the synaptosomal membrane was evaluated by measuring LDH activity, which is a cytosolic marker (38), in the absence and presence of the detergent Triton X-100. In Table I specific activities of $\mathrm{LDH}$ in the absence of Triton $X-100$ were found to be $136 \pm 15.0$ and $150 \pm 15 \mathrm{nmol} / \mathrm{min}$ per $\mathrm{mg}$ of protein in normal and uremic synaptosomal fractions, respectively. These values increased to $995 \pm 35$ and $920 \pm 40$ $\mathrm{nmol} / \mathrm{min}$ of $\mathrm{mg}$ protein, respectively, in the presence of $0.5 \%$ Triton X-100. The sixfold increase of LDH activity after lysis of the synaptosomes demonstrates an intactness of the synaptosomes before lysing with the detergent.

Total internal volume. The internal volume of both normal and uremic synaptosomes was measured before freezing at $-80^{\circ} \mathrm{C}$. No difference was found in the volumes between both groups of synaptosomes and the values of $3.5 \pm 0.6$ and $3.4 \pm 0.4$ $\mu \mathrm{l} / \mathrm{mg}$ of protein (Table II) were similar to those obtained by other investigators (18). During the various uptake experiments, the uptake of $\left[{ }^{3} \mathrm{H}\right]$ mannitol was similar in both the normal and uremic synaptosomes $(76,000 \pm 5,000$ vs. $75,000 \pm 4,000$ $\mathrm{cpm} / \mathrm{mg}$ of protein, respectively).

Oxygen consumption. Table II shows the results of the rate of respiration of the synaptosomes in the media described in the methods section. It is shown that in both normal and uremic synaptosomes the respiratory rates are not significantly different $(4.3 \pm 0.12$ vs. $4.6 \pm 0.2 \mathrm{nmol} / \mathrm{min}$ per $\mathrm{mg}$ of protein, respectively). This similarity was also maintained in the presence of other substrates such as glucose and ADP, but was higher $(22 \pm 2.0 \mathrm{nmol} / \mathrm{min}$ per $\mathrm{mg}$ of protein) in both normal and uremic synaptosomes in the presence of succinate, a substrate for mitochondrial and synaptosomal respiration $(17,34)$.

ATP determinations. ATP determinations were made in six groups of normal and uremic synaptosomes as described above. There was no difference in intravesicular ATP mea-

Table I. Enzyme Activity in Synaptosomes from Normal and Uremic Rat Brain

\begin{tabular}{|c|c|c|c|c|c|}
\hline & \multicolumn{2}{|l|}{ LDH } & \multirow{2}{*}{\multicolumn{2}{|c|}{$\begin{array}{l}\text { NADH NADPH } \\
\text { (cytochrome } c \text { reductase) }\end{array}$}} & \multirow{3}{*}{$\begin{array}{l}\text { Percentage of } \\
\text { mitochondria } \\
\text { contamination } \\
n=3\end{array}$} \\
\hline & \multirow{2}{*}{$\begin{array}{l}(-) \text { Triton } \\
n^{*}=3\end{array}$} & \multirow{2}{*}{$\begin{array}{l}(+) \text { Triton } \\
n=3\end{array}$} & & & \\
\hline & & & $n=3$ & $n=3$ & \\
\hline & \multicolumn{2}{|c|}{ nmol/min per mg protein } & \multicolumn{2}{|c|}{ nmol/min per mg protein } & \\
\hline Normal & $136.0 \pm 15.0$ & $995.0 \pm 35.0$ & $3.3 \pm 0.4$ & $0.6 \pm 0.1$ & $6.4 \pm 0.9$ \\
\hline Uremic & $150.0 \pm 15.0$ & $920.0 \pm 40.0$ & $3.5 \pm 0.5$ & $1.1 \pm 0.3$ & $5.7 \pm 0.6$ \\
\hline
\end{tabular}

Data are expressed as mean \pm SD. * $n$, number of experiments. $¥$ Percentage of mitochondria contamination is based on measured $\mathrm{NADH}$ activity in mitochondria of $42.0 \mathrm{nmol} / \mathrm{min}$ per $\mathrm{mg}$ of protein. 
Table II. Properties of Normal vs. Uremic Synaptosomes

\begin{tabular}{|c|c|c|c|c|}
\hline & \multirow[b]{2}{*}{$\begin{array}{l}\text { Oxygen } \\
\text { consumption } \\
n^{*}=4\end{array}$} & \multirow[b]{2}{*}{$\begin{array}{l}\text { Internal } \\
\text { volume } \\
n=4\end{array}$} & \multicolumn{2}{|c|}{ Ouabain-sensitive component } \\
\hline & & & $\begin{array}{l}\mathrm{K}^{+} \text {uptake } \\
n=5\end{array}$ & $\begin{array}{l}\mathrm{Na}^{+} \text {uptake } \\
n=6\end{array}$ \\
\hline & $\begin{array}{l}\text { nmol/min } \\
\text { per } \mathrm{mg} \\
\text { protein }\end{array}$ & $\begin{array}{l}\mu l / m g \\
\text { protein }\end{array}$ & \multicolumn{2}{|c|}{ nmol/min per mg protein } \\
\hline Normal & $4.3 \pm 0.12$ & $3.5 \pm 0.60$ & $3.4 \pm 0.15$ & $6.1 \pm 0.20$ \\
\hline Uremic & $4.6 \pm 0.20$ & $3.4 \pm 0.40$ & $2.0 \pm 0.10 \ddagger$ & $3.3 \pm 0.20 \S$ \\
\hline
\end{tabular}

Data is expressed as mean \pm SD.

* $n$, number of experiments.

$\ddagger P<0.005$ versus normal.

$\S P<0.001$ versus normal.

surements in both normal and uremic synaptosomes $(0.34 \pm 0.12$ vs. $0.35 \pm 0.11 \mathrm{mM}$, respectively).

Veratridine-stimulated sodium uptake. To assess the ability of uremic synaptosomes to transport sodium, we first evaluated sodium uptake in normal synaptosomes, using radioactive ${ }^{22} \mathrm{Na}$ as a tracer. In Fig. 1, the middle curve shows the amount of sodium taken up over time by the normal synaptosomes, without addition of either veratridine or tetrodotoxin. Rapid sodium uptake occurred within the first $5 \mathrm{~min}$ to $90 \%$ of its maximum value and increased very slowly thereafter to a plateau at $\sim 10 \mathrm{~min}$. The final uptake concentration at 10 min was $2.18 \pm 0.2 \mathrm{nmol} / \mathrm{mg}$ of protein. With the addition of $50 \mu \mathrm{M}$ veratridine, there was a doubling of the sodium uptake at $5 \mathrm{~min}$ from $2.18 \pm 0.2$ to $4.12 \pm 0.3 \mathrm{nmol} / \mathrm{mg}$ of protein. Not only was there an increase in the amount of sodium taken up, but it was taken up at a faster rate, reaching a peak value by

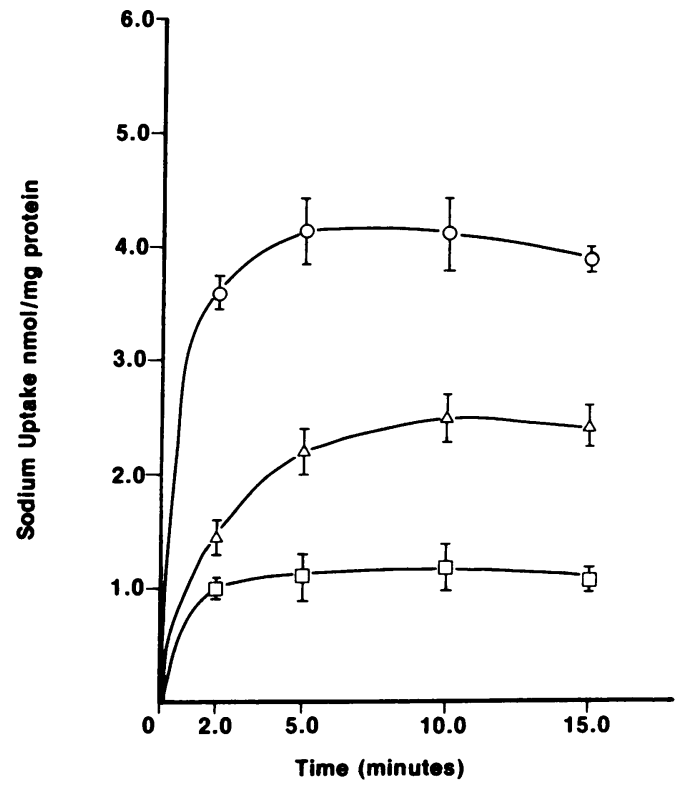

Figure 1. Sodium uptake in synaptosomes from normal rat brain. With veratridine stimulation (0), $\mathrm{Na}^{+}$uptake is significantly greater than in control $(\Delta)(P<0.001)$. With the addition of veratridine and tetrodotoxin $(\square)$, the uptake was significantly inhibited $(P<0.001)$. This graph is a mean of six experiments, and each time point was done in triplicate. Data are presented as mean \pm SD.
$5 \mathrm{~min}$. This effect of veratridine on synaptosomal sodium uptake indicates operation of a voltage-sensitive sodium channel facilitated by veratridine (39), which selectively increases the resting membrane permeability to sodium. This results in rapid accumulation of sodium and is similar to results published by others $(24,40,41)$. As shown in the bottom curve the addition of $1 \mu \mathrm{M}$ tetrodotoxin in addition to $50 \mu \mathrm{M}$ veratridine not only completely inhibited the veratridine stimulated sodium uptake but most of the unstimulated sodium uptake as well. This is consistent with work done by Rojas and Atwater (42), who found tetrodotoxin to be a specific blocker of the early inward and outward currents carried by sodium in neural membranes.

A similar experiment was carried out using synaptosomes from uremic rats. Fig. 2 shows the uptake pattern in this experiment. In comparing Fig. 2 with Fig. 1 both the control sodium uptake and the degree of inhibition by $1 \mu \mathrm{M}$ tetrodotoxin were not significantly different from normal. The veratridine-stimulated sodium uptake in the uremic synaptosomes after $2 \mathrm{~min}$, however, was significantly increased $(P<0.001)$ when compared with normal $(4.12$ vs. $5.53 \mathrm{nmol} / \mathrm{mg}$ of protein, respectively). The distribution of the curves over time is similar in both figures and the difference can be more clearly appreciated in Fig. 3.

In Fig. 3 is plotted the difference between veratridinestimulated sodium uptake and the control uptake in both groups of synaptosomes. The top curve shows the relative increase in sodium uptake in uremic synaptosomes over that seen in normal synaptosomes. The time points indicated by the asterisks are significantly different $(P<0.001)$.

Two possible mechanisms were considered likely to explain the difference between normal and uremic veratridine-stimu-

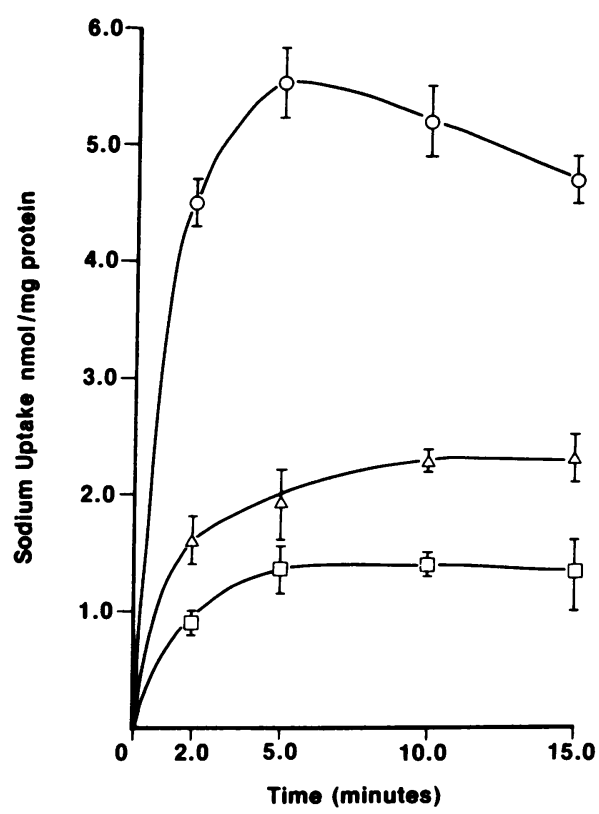

Figure 2. Sodium uptake in synaptosomes from uremic rat brain. With veratridine stimulation (O), $\mathrm{Na}^{+}$uptake is significantly greater than in control $(\Delta)(P<0.001)$. With the addition of tetrodotoxin in addition to veratridine $(\square)$, both the stimulated and unstimulated $\mathrm{Na}^{+}$uptake are significantly inhibited. This graph is a mean of six experiments, and each time point was done in triplicate. Data are presented as the mean $\pm \mathrm{SD}$. 


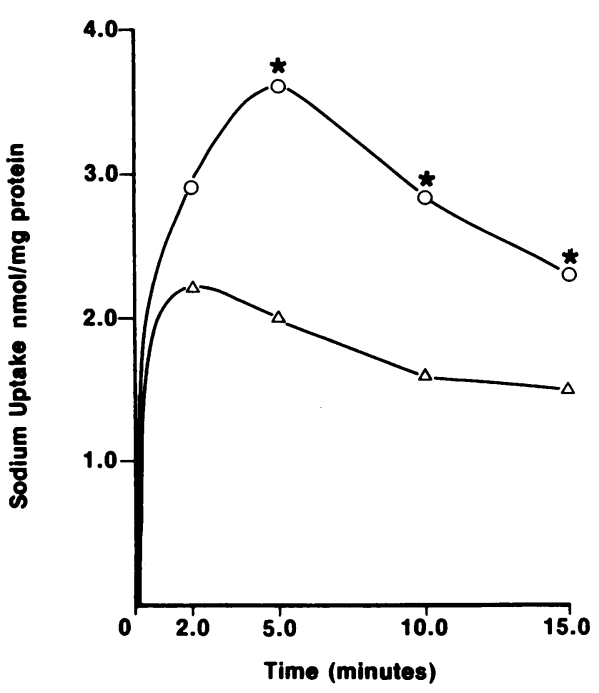

Figure 3. In this graph is plotted the difference between the veratridine-stimulated $\mathrm{Na}^{+}$uptake and the control uptake (without additions of neurotoxins) in both groups of synaptosomes. The top curve (o) shows the veratridine-stimulated sodium uptake in uremic synaptosomes, whereas the uptake in normal synaptosomes is represented by the lower curve $(\Delta)$. The increased veratridine-stimulated sodium uptake in uremic rats is significantly less than in normal $(*, P$ $<0.001$ ) at 5, 10, and $15 \mathrm{~min}$. Data for Fig. 3 are obtained from Fig. 1 and Fig. 2.

lated sodium uptake: $(a)$ increased synaptosomal membrane permeability to sodium in the uremic synaptosomes, allowing more sodium to enter the vesicles. This could be due to an increase in the size and/or number of opened sodium channels or be due to an increase in the membrane permeability to sodium irrespective of the available sodium channels. (b) Inability of the accumulated sodium to leave the synaptosomes; this would suggest a decrease in the activity of the $\mathrm{Na}-\mathrm{K}$ ATPase pump.

Membrane permeability studies. We evaluated membrane permeability by studying the effect of valinomycin on veratri-

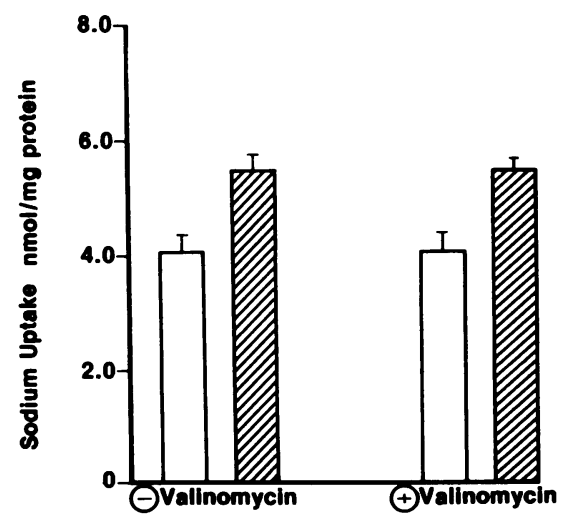

Figure 4. Veratridine-stimulated $\mathrm{Na}^{+}$uptake in the presence and absence of valinomycin at $5 \mathrm{~min}$. The hatched rectangle represents $\mathrm{Na}^{+}$uptake in uremic synaptosomes; the open rectangle, $\mathrm{Na}^{+}$uptake in normal synaptosomes. No significant difference in sodium uptake pattern was observed with or without $25 \mu \mathrm{M}$ valinomycin. This graph is the mean of five experiments. Data are presented as mean \pm SD.

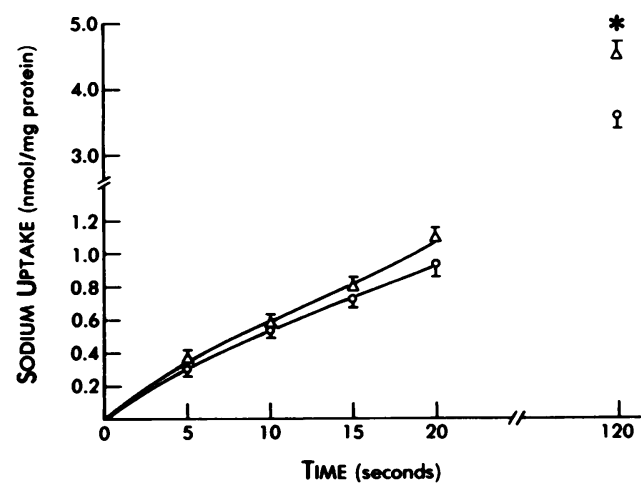

Figure 5. Veratridine-stimulated sodium uptake in normal and uremic synaptosomes between 0 and $120 \mathrm{~s}$. No significant difference in uptake was observed between both normal $(0)$ and uremic synaptosomes $(\Delta)$ within $20 \mathrm{~s}$. At $120 \mathrm{~s}$, however, the difference was significant $(*, P<0.005)$. Study is a mean of seven experiments. Data are presented as mean $\pm \mathrm{SE}$.

dine-stimulated sodium uptake. The experiment was carried out as discussed in Methods. The synaptosomes were loaded in a $150-\mathrm{mM}$ potassium chloride solution. The suspension was then incubated in an external media containing no potassium and $25 \mu \mathrm{M}$ valinomycin, a known potassium ionophore. The result of this experiment (Fig. 4) shows that the difference in veratridine-stimulated sodium uptake between normal and uremic synaptosomes is maintained. This suggests that the increased veratridine-stimulated sodium uptake observed in uremic synaptosomes does not appear to be caused by changes in synaptosomal membrane permeability to potassium. To further assess membrane permeability, we evaluated initial rate of sodium uptake in both groups of synaptosomes during the time points of $0-120 \mathrm{~s}$. As shown in Fig. 5, no significant difference in uptake was observed in the first $20 \mathrm{~s}$; however, at $2 \mathrm{~min}$ the difference became significant. Based on these two experiments it appears that the increased sodium accumulation in uremia is not due to increased uptake of sodium but to decreased efflux of sodium from the uremic synaptosomes.

Potassium uptake. We first attempted to evaluate the $\mathrm{Na}$ K ATPase pump activity by looking at the ability of both groups of synaptosomes to take up potassium (Fig. 6). The synaptosomes were loaded with $150 \mathrm{mM} \mathrm{NaCl}$ preequilibrium media, as discussed above and uptake was carried out at $25^{\circ} \mathrm{C}$. As shown previously by others $(23,30,31)$, rubidium is interchangable with potassium for uptake by the $\mathrm{Na}-\mathrm{K}$ ATPase pump in synaptosomes, and the permeability of the synaptosomal membrane for rubidium is the same as that for potassium. In addition, there is a relative instability of radioactive potassium. For these reasons we elected to use ${ }^{86} \mathrm{Rb}$ as a tracer in these experiments. If there is disfunction of the Na-K ATPase pump, then the expected potassium uptake in uremia should be less than that observed in normal synaptosomes.

The top curve in Fig. 6 illustrates the potassium uptake in normal synaptosomes and the bottom curve shows the uptake in the uremic synaptosomes. Uptake reached a maximum at $5 \mathrm{~min}$ in both groups but potassium uptake in the uremic synaptosomes was only $78 \%$ of normal $(6.0 \mathrm{vs.} 7.70 \mathrm{nmol} / \mathrm{mg}$ of protein) and was significantly less than normal $(P<0.005)$ between 2 and $15 \mathrm{~min}$. It could be suggested however, that the decreased potassium accumulation in uremic synaptosomes may be due to a decreased amount of available intravesicular 


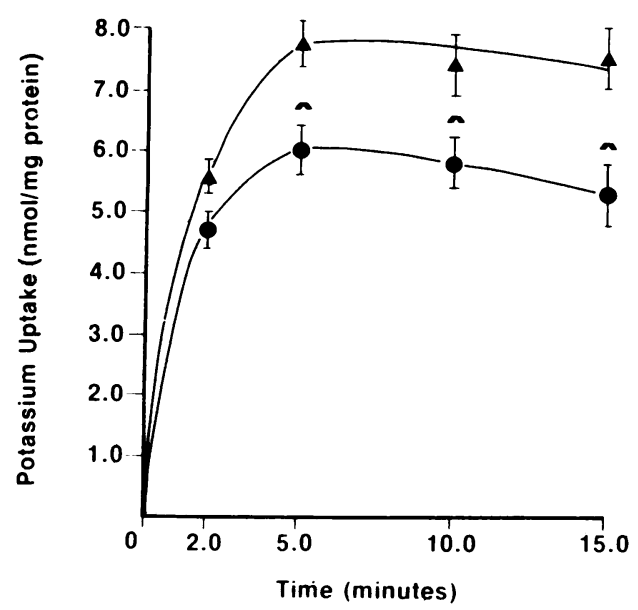

Figure 6. Graph compares potassium uptake in synaptosomes of normal and uremic rat brain plotted against time. The top curve ( $\Delta$ ) shows the uptake pattern in normal synaptosomes. The bottom curve (•) illustrates the decreased potassium uptake in uremia, which is significantly less than in normal $(\wedge, P<0.005)$ at 5,10 , and $15 \mathrm{~min}$. This is the mean of four experiments. Data are presented as mean \pm SD.

ATP. Based on our measurements of ATP, however, this appears to be unlikely. In the presence of $2.5 \mathrm{mM}$ ouabain (Fig. 7), potassium uptake was inhibited to 4.3 and $4.0 \mathrm{nmol} /$ $\mathrm{mg}$ of protein in the normal and uremic synaptosomes, respectively. Thus, the ouabain-sensitive component of potassium uptake in normal synaptosomes is significantly greater than in uremic synaptosomes (Table II). This finding indicates that uremic synaptosomes have a decreased ability to accumulate potassium when compared with normal, and the uptake is ouabain sensitive. Such a result strongly suggests an abnormal function of the Na-K ATPase pump.

ATP-stimulated sodium uptake. To evaluate further the action of the Na-K ATPase pump, we decided to look at the ATP-stimulated sodium uptake in inverted synaptosomes. During the preparation of the synaptosomes a fraction of the

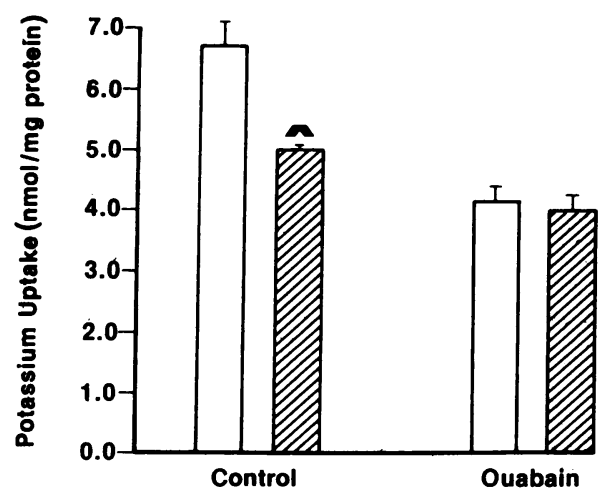

Figure 7. Potassium uptake at $5 \mathrm{~min}$ in synaptosomes from both normal $(\square)$ and uremic $(\square)$ rats, in the presence and absence of ouabain. Without ouabain, $\mathrm{K}^{+}$uptake in uremia is significantly less than in normal $(\wedge, P<0.005)$. With $2.5 \mathrm{mM}$ ouabain, $\mathrm{K}^{+}$uptake is inhibited to a level such that the uptake in normal and uremic synaptosomes is not significantly different. Data are presented as mean \pm SD.

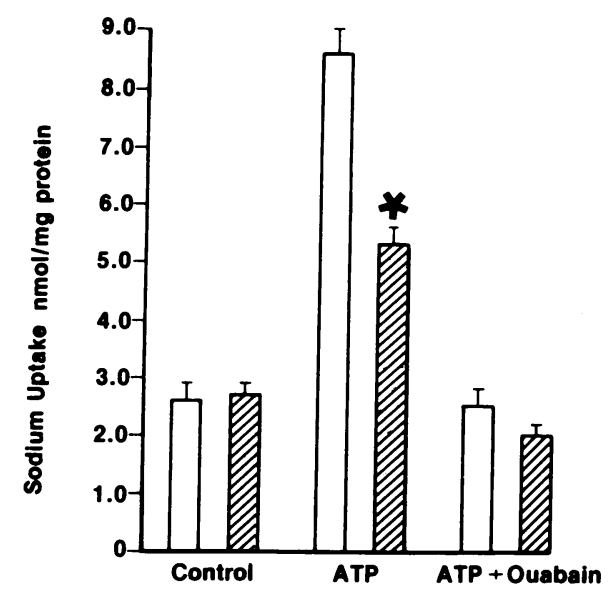

Figure 8. ATP-stimulated sodium uptake in inverted synaptosomes at $5 \mathrm{~min}$. $\mathrm{Na}^{+}$uptake in uremic synaptosomes is represented by the hatched rectangles; in normal synaptosomes, by the open rectangles. Uptake was carried out in synaptosomes in the presence of $2.5 \mathrm{mM}$ ATP in the external media, with or without $2.5 \mathrm{mM}$ ouabain. The ATP-stimulated $\mathrm{Na}^{+}$uptake is significantly less in uremia than in normal $(*, P<0.001)$. The uptake is inhibited by ouabain in both groups of synaptosomes. Five experiments were carried out in this study. Data are presented as mean \pm SD.

synaptosomes was reformed in an inverted manner. This occurs as a result of homogenation and freeze thawing (19), and this population of synaptosomes was used in this experiment. The synaptosomes were loaded with a $150 \mathrm{mM} \mathrm{KCl}$ media as discussed in Methods, and uptake was stimulated by the addition of $2.5 \mathrm{mM}$ Tris-ATP to the external media. As shown in Fig. 8, at 5 min, ATP-stimulated sodium uptake was increased to $3 \frac{1 / 2}{2}$ times the control value in normal synaptosomes ( $2.6 \mathrm{vs} .8 .6 \mathrm{nmol} / \mathrm{mg}$ of protein), as compared with an increase to only two times control in the uremic synaptosomes $(2.70$ vs. $5.3 \mathrm{nmol} / \mathrm{mg}$ of protein). The observed decreased sodium uptake in uremia is significantly less than in normal $(P$ $<0.001$ ). With the addition of $2.5 \mathrm{mM}$ ouabain to the external media containing $2.5 \mathrm{mM}$ ATP, the stimulation was completely inhibited (Fig. 8). Sodium uptake in both groups of synaptosomes returned to control values. The ouabain-sensitive component of sodium uptake in normal synaptosomes is significantly greater than that observed in uremia (Table II). This data supports the result of the potassium experiment and again strongly suggests an abnormality of the Na-K ATPase pump. We evaluated the nature of the ATP-dependent sodium uptake in this system by looking at initial sodium uptake between 0 and $30 \mathrm{~s}$. No difference was found between normal and uremic synaptosomes over the first $15 \mathrm{~s}$; however, at 20 and $30 \mathrm{~s}$ (Fig. 9) sodium uptake in the uremic synaptosomes is significantly less than normal $(P<0.01)$.

Effects of ouabain on veratridine-stimulated sodium uptake. In this experiment (Fig. 10), the veratridine-stimulated sodium uptake previously observed in synaptosomes is completely inhibited. Also the difference between normal and uremic synaptosomal sodium uptake was eliminated by ouabain. This suggests that veratridine stimulation may be acting in association with the Na-K ATPase pump. Furthermore, complete inhibition of the Na-K ATPase pump results in no veratridine-stimulated sodium uptake by the synaptosomes.

Veratridine-stimulated sodium uptake in choline chloride- 


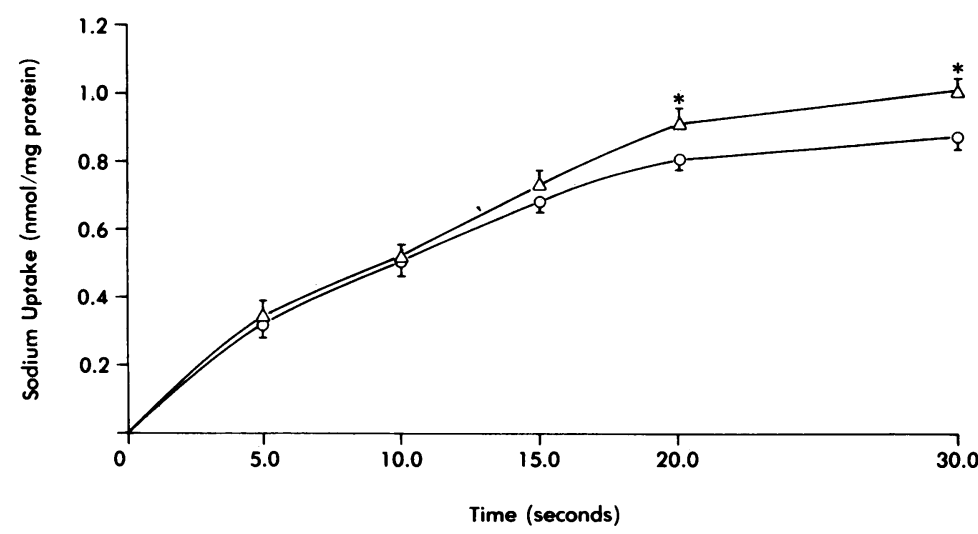

Figure 9. This graph compares ATP-dependent sodium uptake in normal and uremic synaptosomes plotted against time in seconds. The top curve $(\Delta)$ shows sodium uptake in normal synaptosomes. The bottom curve $(0)$ shows sodium uptake in uremic synaptosomes. A significant difference in uptake was observed between these groups at 20 and $30 \mathrm{~s}(*$, $P<0.01)$. The experiment was performed in 15 experiments and as in all experiments each time point was done in triplicate. Data are presented as mean \pm SE. loaded vesicles. Synaptosomal membranes are quite impermeable to choline chloride (30). Because of this property, we decided to evaluate veratridine-stimulated sodium uptake in vesicles loaded with choline chloride. This would serve two purposes: $(a)$ to eliminate the passive sodium-potassium exchange, which is seen in the unstimulated state (Figs. 1 and 2) and $(b)$ to inactivate the Na-K ATPase pump. As shown in Fig. 11, the effect of veratridine stimulation was similar to that seen when potassium-loaded vesicles were treated with ouabain. Again the requirement of a functioning $\mathrm{Na}-\mathrm{K}$ pump to facilitate veratridine-stimulated sodium uptake is apparent.

\section{Discussion}

The data presented in this paper show a significant difference in veratridine-stimulated sodium accumulation between normal and uremic synaptosomes. The increased veratridine-stimulated sodium accumulation observed in the uremic synaptosomes does not appear to be due to the effects of uremic milieu per se, because the synaptosomes were prepared, stored, and studied in a nonuremic environment. Rather, it appears that the uremic state resulted in an alteration of synaptosomal function, which leads to an increased veratridine-stimulated sodium accumulation. Furthermore, it appears that this defect in sodium accumulation is caused by an abnormality in the Na-K ATPase pump function. This defect in pump activity results in decreased extrusion of sodium.

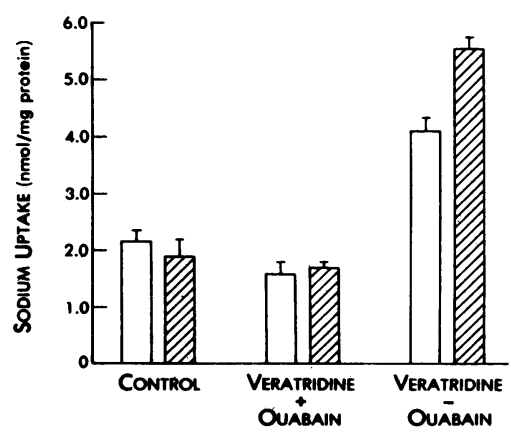

Figure 10. Effect of ouabain on veratridine-stimulated sodium uptake. Graph shows control (unstimulated) uptake, and veratridinestimulated sodium uptake in the presence and absence of ouabain. Ouabain completely inhibited veratridine-stimulated sodium uptake. Uptake was measured in five groups of synaptosomes at $5 \mathrm{~min}$. Sodium uptake in uremia is represented by hatched rectangles; in normal, by open rectangles. Data are presented as mean \pm SD.
This conclusion is based on the following observations: $(a)$ The ouabain-sensitive component of both the ATP-stimulated sodium uptake and the potassium uptake were significantly less in the uremic synaptosomes than in normal. $(b)$ When the potassium conductance was maintained constant during the uptake process, by the addition of valinomycin (a potassium ionophore) to the external media, the difference in veratridinestimulated sodium accumulation between both groups of synaptosomes remained unchanged. This suggested that the increased sodium accumulation in uremic synaptosomes was probably not due to differences in potassium conductance but to decreased ability of the pump to extrude sodium in exchange for potassium. (c) Initial ATP-stimulated sodium uptake in inverted synaptosomes is significantly less in uremic than in normal vesicles. However, veratridine-stimulated sodium uptake at these early points was not significantly different when comparing normal and uremic synaptosomes. (d) Finally, during the experiments, the intravesicular volume and other physical properties of the vesicles (Table II) were not significantly different between both groups of synaptosomes.

We used veratridine to stimulate sodium uptake in our experiments because of work done previously by other investigators $(31,39)$ in rat brain synaptosomes. Veratridine was found to selectively increase the resting membrane permeability to sodium by operation of a voltage-sensitive sodium channel, and this was postulated to be a potassium-dependent process. It was therefore possible that the increased veratridine-stimulated sodium uptake found in uremic synaptosomes (Figs. 1

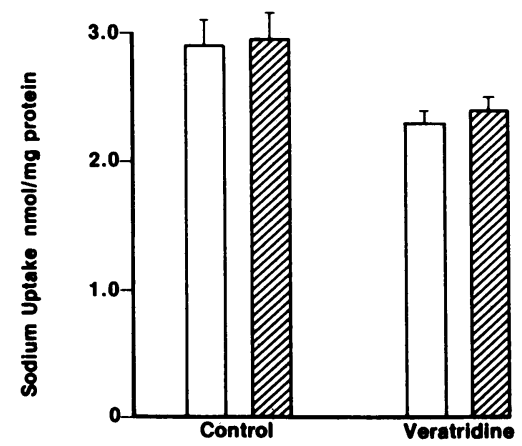

Figure 11. Veratridine-stimulated sodium uptake in synaptosomes loaded with choline chloride. As with ouabain no veratridine stimulation was observed in these vesicles. This graph is a mean of five experiments performed at $5 \mathrm{~min}$. The hatched rectangle denotes sodium uptake in uremic synaptosomes; the open rectangle, uptake in normal synaptosomes. Data are presented as mean $\mathrm{SD}$. 
and 2) could be due to a further increase in the membrane permeability to potassium. However, this does not appear to be the case in our preparation in that addition of valinomycin to the system did not appreciably alter the pattern of sodium uptake.

With regards to the orientation of our vesicles we believe that they are primarily physiologically oriented (right side out). Previously (42), other investigators have found tetrodotoxin to block the early inward and outward current carried by sodium, potassium, or lithium ions across synaptosomal membranes. This suggested that the action of tetrodotoxin on sodium uptake was an immediate inhibition of both the stimulated and unstimulated uptake. In previous sodium uptake studies on inverted synaptosomal plasma membranes (from guinea pig cerebral cortex) (24), it was found that the inhibitory character of tetrodotoxin was time-dependent and that it only partially inhibited the veratridine-stimulated sodium uptake. It was felt that the inverted nature of most of their preparation made them only partially exposed to tetrodotoxin, and hence accounted for the relative insensitivity to tetrodotoxin. In our preparation only $\sim 30 \%$ of the synaptosomes appear to be inverted. This may explain the significant degree of inhibition of both the unstimulated and veratridine-stimulated Na uptake that we found (Figs. 1 and 2).

To understand the mechanism by which sodium is accumulated in vesicles under veratridine stimulation, we measured veratridine-stimulated sodium uptake in synaptosomes treated with $2.5 \mathrm{mM}$ ouabain. As shown in Fig. 10, not only was the stimulatory effect of veratridine eliminated by ouabain, but in addition, the difference between normal and uremic synaptosomal sodium uptake was obliterated. The question, therefore, is whether veratridine-stimulated sodium transport is either dependent on the Na-K ATPase pump or the mechanisms are mutually exclusive. On the basis of both the ouabain experiment and the effect of veratridine on uremic synaptosomes, it is apparent that veratridine-stimulated sodium uptake is largely dependent on the action of the Na-K ATPase pump. It is also apparent that complete obliteration of pump function eliminated the veratridine stimulation of sodium uptake (Fig. 10). However, impaired function of the Na-K ATPase pump (as observed in uremia, Fig. 2) causes increased accumulation of sodium.

To test this hypothesis we evaluated veratridine-stimulated sodium uptake in synaptosomes loaded with choline chloride. In these vehicles the effects of choline chloride would be expected to $(a)$ eliminate the passive $\mathrm{Na}-\mathrm{K}$ exchange that occurs in both inside-out and right-side-out vesicles and $(b)$ inactivate the Na-K ATPase pump. This would therefore both eliminate the veratridine effect and also obliterate the difference seen previously between normal and uremic sodium uptake. As shown in Fig. 11, there is complete inhibition of the veratridine effect. It can therefore be concluded that veratridinestimulated uptake depends on the function of the Na-K ATPase pump.

The major contaminants of a synaptosome preparation are mitochondria, synaptic vesicles, external membranes, endoplasmic reticulum, Golgi apparatus, and lysosomes (23). Of these the only one that is of real significance is free mitochondria. Mitochondria are found in nerve terminals, some of which are released by the shearing forces of homogenization. The mitochondria are easily separated from the synaptosomes as they are smaller $(0.1-\mu \mathrm{m}$ diameter) and more dense than the synaptosomes (16). The synaptosomes are quite large, measuring $\sim 0.6-1.2 \mu \mathrm{m}$ in diameter (43) and contain approximately from zero to four mitochondria which on an average is $\sim 24 \%$ of the synaptosomal volume (43). The degree of contamination by free mitochondria in our synaptosomal preparation (Table I) is well within the limits observed by other investigators $(16,44)$.

In performing bilateral uretheral ligation under anesthesia, the rats were allowed to breath room air. They were anesthetized for $\sim 20$ min during which time their arterial $\mathrm{PO}_{2}$ went from 95 to $75 \mathrm{mmHg}$. Numerous investigators have studied the effects of anesthesia and hypoxia on synaptosomes of rat brain and have found no permanent alteration in the rate of oxygen consumption and energy use (44-46). It also has been shown that there is a temporary decrease in oxygen consumption and ATP synthesis in synaptosomes both in starved rats subjected to $30 \mathrm{~min}$ of $7 \%$ oxygen $\left(\mathrm{PO}_{2} 27.5 \mathrm{mmHg}\right)$ and in anesthetized rats. However, these changes were normalized by feeding the animals before hypoxia or by returning them to a normal oxygen environment (44). From these observations it does not appear that the anesthesia contributed significantly to the alteration of the Na-K ATPase pump activity that we observed.

The effects of uremia on both the central nervous system and erythrocytes have been studied in rats and humans. Minkoff and associates (15) demonstrated a significantly decreased $\mathrm{Na}-\mathrm{K}$ ATPase enzyme activity in a crude microsomal fraction from the brain of acutely uremic rats. They showed that the depressed enzyme activity was not due to acidosis but was attributable to the uremic state. Unlike Minkoff et al., however, van den Noort and associates (14) found no significant differences in cation responsive ATPase activity in normal and uremic rat brain. Other investigators (11) have shown that there is decreased sodium transport across the red cell membrane in uremic patients. Izumo and associates (47) found that there was impaired function of the erythrocyte $\mathrm{Na}-\mathrm{K}$ ATPase pump in uremia. They suggested that the impairment of the Na-K ATPase pump was due to a nonouabain-like circulating factor which was markedly diminished by acute hemodialysis (47).

Wood and associates (13) found that the rate of $\mathrm{Na}^{+}-\mathrm{Li}^{+}$ countertransport was reduced in erythrocytes. Similarly, Cotton and associates suggested that the resting skeletal muscle membrane potential is altered in uremia (48). Unlike in our study, these abnormalities were reversed by removal of the uremic environment. All these studies suggest that there are intrinsic functional defects in various membranes in uremia, both in humans and animals. Our finding of a decreased Na-K ATPase pump activity is consistent with these observations, and may be a significant factor in the observed central nervous system manifestation of uremia.

In summary, we have shown that, in synaptosomes from the brains of uremic rats, there is an increase in veratridinestimulated sodium accumulation over control animals. This increased sodium accumulation is most likely due to an alteration in the Na-K ATPase pump. The defect does not appear to be due to a uremic milieu per se, but rather to an effect of uremia that alters synaptosomal function. In uremia, central nervous system function is impaired and is only partially corrected by dialytic therapy which corrects the abnormalities found with a uremic milieu (elevated blood urea nitrogen and creatinine, metabolic acidosis). Thus, these abnormalities of synaptosomal function may be related to some 
of the central nervous system abnormalities present in the uremic state.

\section{Acknowledgments}

The authors thank Ms Velma Tyler for preparation of the manuscript. This research was supported by grant AM-28127 from the National Institute of Arthritis, Diabetes, Digestive and Kidney Diseases, U. S. Public Health Service, and by the Research Service of the Veterans Administration Medical Center, San Francisco, CA.

\section{References}

1. Teschan, P. E., and A. I. Arieff. Uremic and dialysis encephalopathies. In Cerebral Energy Metabolism and Metabolic Encephalopathy. D. W. McCandless, editor. Plenum Publishing Corp., New York. In press.

2. Arieff, A. I. 1985. Effects of water, electrolyte and acid base disorders on the central nervous system. In Fluid, Electrolyte and Acid Base Disorders. A. I. Arieff and R. A. DeFronzo, editors. Churchill Livingstone, New York. 969-1039.

3. Mahoney, C. A., and A. I. Arieff. 1983. Central and peripheral nervous system effects of chronic renal failure. Kidney Int. 24:170177.

4. Mahoney, C. A., P. Sarnacki, and I. Arieff. 1984. Uremic encephalopathy: Role of brain energy metabolism. Am. J. Physiol. 247:F527-F532.

5. Fishman, R. A. 1970 . Permeability changes in experimental uremic encephalopathy. Arch. Intern. Med. 126:835-837.

6. Arieff, A. I., and S. G. Massry. 1974. Calcium metabolism of brain in acute renal failure: effects of uremia, hemodialysis and parathyroid hormone. J. Clin. Invest. 53:387-392.

7. Guisado, R., A. I. Arieff, and S. G. Massry. 1975. Changes in the electroencephalogram in acute uremia: Effects of parathyroid hormone and brain electrolytes. J. Clin. Invest. 55:738-745.

8. Cooper, J. D., V. C. Lazarowitz, and A. I. Arieff. 1978 Neurodiagnostic abnormalities in patients with acute renal failure Evidence for neurotoxicity of parathyroid hormone. J. Clin. Invest. 61:1448-1455.

9. Alfrey, A. C., Gr. R. LeGendre, and W. D. Kaehny. 1976. The dialysis encephalopathy syndrome. Possible aluminum intoxication. $N$. Engl. J. Med. 294:184-188.

10. Cogan, M., C. Covey, A. I. Arieff, A. Wisniewski, O. Clark, V. C. Lazarowitz, and W. Leach. 1978. Central nervous system manifestations of hyperparathyroidism. Am. J. Med. 65:963-970.

11. Welt, L. G., J. R. Sachs, and T. J. McManus. 1964. An ion transport defect in erythrocytes from uremic patients. Trans. Assoc. Am. Physicians. 77:169-181.

12. Cole, C. H., J. W. Balfe, and L. G. Welt. 1968. Induction of a ouabain-sensitive ATPase defect by uremic plasma. Trans. Assoc. Am. Physicians. 81:213-220.

13. Woods, J. W., J. C. Parker, and B. S. Watson. 1983. Pertubation of sodium-lithium countertransport in red cells. $N$. Engl. J. Med. 308: 1258-1261.

14. van den Noort, S., R. E. Eckel, K. Brine, and J. T. Hrdlicka. 1968. Brain metabolism in uremic and adenosine-infused rats. J. Clin. Invest. 47:2133-2142.

15. Minkoff, L., G. Gaertner, M. Darah, C. Mercier, and M. L. Levin. 1972. Inhibition of brain sodium-potassium ATPase in uremic rats. J. Lab. Clin. Med. 80:71-78.

16. Booth, R. F. G., and J. B. Clark. 1978. A rapid method for the preparation of relatively pure metabolically competent synaptosomes from rat brain. Biochem. J. 176:365-370.

17. Whittaker, V. P. 1969. The synaptosome. In Handbook of Neurochemistry, Vol. II. A. Lajtha, editor. Plenum Press, New York. 327-364.

18. Deutsch, C., C. Drown, U. Rafalowska, and I. A. Silver. 1981.
Synaptosomes from rat brain. Morphology, compartmentation, and transmembrane pH and electrical gradients. J. Neurochem. 36:20632072.

19. Whittaker, V. P., I. A. Michaelson, R. Jeanette, and A. Kirkland. 1964. The separation of synaptic vesicles from nerve-endings particles (synaptosomes). Biochem. J. 90:293-303.

20. de Belleroche, J. S., and H. F. Bradford. 1973. Metabolism of beds of mammalian cortical synaptosomes. Response to depolarizing influences. J. Neurochem. 19:585-602.

21. Marchbanks, R. M. 1975. The chloride content, anion deficit and volume of synaptosomes. J. Neurochem. 25:463-470.

22. Cotman, C. W., J. W. Haycock, and W. F. White. 1976. Stimulus secetion in brain. Analysis of noradrenaline and gaba release. J. Physiol. (Lond.). 244:475-505.

23. Scott, I. D., and D. G. Nicholas. 1980. Energy transduction in synaptosomes: Influence of plasma-membrane depolarization on the respiration and membrane potential of internal mitochondria determined in situ. Biochem. J. 186:21-33.

24. Gill, D. L. 1982. Sodium channel, sodium pump, and sodiumcalcium exchange activities in synaptosomal plasma membrane vesicles. J. Biol. Chem. 257:10986-1908.

25. Gray, E. G., and V. P. Whittaker. 1962. The isolation of nerve endings from brain. J. Anat. 96:79-87.

26. Lowry, O. H., N. J. Rosebrough, A. L. Farr, and R. J. Randall. 1951. Protein measurements with the Folin-phenol reagent. J. Biol. Chem. 193:265-275.

27. Padan, E., D. Zilberstein, and H. Rottenberg. 1976. The proton electrochemical gradient in Escherichia coli cells. Eur. J. Biochem. 63; 533-541.

28. Eveloff, J., and R. Kinne. 1983. Sodium-chloride transport in the medullary thick ascending limb of Henle's loop. Evidence for a sodium-chloride cotransport system in plasma membrane vesicles. $J$. Membr. Biol. 72:173-181.

29. Lowry, O. H., and J. V. Passonneau. 1972. Collection of metabolite assay. In A Flexible System of Enzymatic Analysis. $\mathbf{O}$. $\mathrm{H}$. Lowry and J. V. Passonneau, editors. Academic Press Inc., New York. 146.

30. Keen, P., and T. D. White. 1976. The permeability of pinched off nerve endings to sodium, potassium and chloride and the effects of gramiciden. J. Neurochem. 18:1097-1103.

31. Blaustein, M. P., and J. M. Goldring. 1975. Membrane potentials in pinched off presynaptic nerve terminals monitored with fluorescent probe: Evidence that synaptosomes have potassium diffusion potentials. J. Physiol. (Lond.). 247:589-615.

32. Duncan, H. M., and B. Mackler. 1966. Electron transport systems of yeast. J. Biol. Chem. 241:1694-1697.

33. Omura, T., and S. Takesue. 1970. A new method for simultaneous purification of cytochrome b5 and NADPH-cytochrome $c$ reductase from rat liver microsomes. J. Biochem. 67:249-257.

34. Clark, J. B., and W. J. Nicklas. 1970. The metabolism of rat brain mitochondria. J. Biol. Chem. 245:4724-4731.

35. Bergmeyer, H. U., H. Klotzsch, H. Mollering, M. NelbockHochstetter, and K. Beauchamp. 1965. Section D. Biochemical reagents. In Methods of Enzymatic Analysis. H. U. Bergmeyer, editor. Academic Press, Inc., New York. 1011.

36. Gurd, J. W., L. R. Jones, H. R. Mahler, and W. J. Moore. 1974. Isolation and partial characterization of rat brain synaptic plasma membranes. J. Neurochem. 22:281-290.

37. Beattie, D. S. 1968. Enzyme localization in the inner and outer membranes of rat liver mitochondria. Biochem. Biophys. Res. Commun. 31:901-907.

38. Johnson, M. K., and V. P. Wittaker. 1963. Lactate dehydrogenase as a cytosolic marker in brain. Biochem. J. 88:404-409.

39. Otha, M., T. Narahashi, and R. F. Keeler. 1973. Effects of veratrum alkaloids on membrane potential and conductance of squid and crayfish giant axons. J. Pharmacol. Exp. Ther. 184:143-154.

40. Kanner, B. I. 1980. Modulation of neurotransmitter transport 
by the activity of the action potential sodium ion channel in membrane vesicles from rat brain. Biochemistry. 19:692-679.

41. Buonanno, A., and R. Villegas. 1983. Sodium channel activity in brain membrane fractions isolated from rats of different ages. Biochim. Biophys. Acta. 730:161-172.

42. Rojas, E., and I. Atwater. 1967. Effects of tetrodotoxin on early outward currents in perfused giant axons. Proc. Natl. Acad. Sci. USA. 57:1350-1355.

43. Whittaker, V. P. 1967. The morphology of fractions of rat forebrain synaptosomes separated on continuous sucrose density gradients. Biochem. J. 106:412-417.

44. Rafalowska, U., M. Erecinska, and D. F. Wilson. 1980. Energy metabolism in rat brain synaptosomes from nembutal-anesthetized and nonanesthetized animals. J. Neurochem. 34:1380-1386.
45. Pastuszko, A., D. F. Wilson, M. Erecinska, and I. A. Silver. 1981. Effects of in vitro and lowered $\mathrm{pH}$ on potassium fluxes and energy metabolism in rat brain synaptosomes. J. Neurochem. 36:116123.

46. Lewis, L. D., U. Ponten, and B. K. Siesjo. 1973. Arterial acidbase changes in unanesthetized rats in acute hypoxia. Respir. Physiol. 19:312-321.

47. Izumo, H., S. Izumo, M. DeLuise, and J. S. Flier. 1984. Erythrocyte Na-K ATPase pump in uremia. Acute correction of a transport defect by hemodialysis. J. Clin. Invest. 74:581-588.

48. Cotton, J. R., T. Woodman, N. W. Carter, and J. P. Knochel. 1979. Resting skeletal muscle membrane potential as an index of uremic toxicity. J. Clin. Invest. 63:501-506. 